\title{
Seneca Valley Virus and Vesicular Lesions in a Pig with Idiopathic Vesicular Disease
}

\author{
Singh $\mathbf{K}^{1 *}$, Corner $\mathbf{S}^{1}$, Clark SG ${ }^{2}$, Scherba $\mathbf{G}^{1}$, and Fredrickson $\mathbf{R}^{1}$ \\ ${ }^{1}$ Veterinary Diagnostic Laboratory, University of Illinois, Urbana-Champaign, IL 61802, USA \\ ${ }^{2}$ Virginia-Maryland Regional College of Veterinary Medicine, Blacksburg, VA 24061, USA
}

\begin{abstract}
Swine Idiopathic Vesicular Disease (SIVD) syndrome is characterized by the formation of ulcers, erosions and vesicles on the skin, coronary bands and in the oral cavity of pigs. The clinical importance of SIVD is its resemblance with vesicular foreign animal diseases. Although the etiology of SIVD remains unknown, Seneca Valley virus, which belongs to the family Picornaviridae, was previously identified in such pigs. Here, we report gross and histopathologic findings in a 6-month-old intact male Chester White boar presented with a history of anorexia, lethargy and lameness. Intact and ruptured vesicles, erosions and ulcers were clinically observed within the oral cavity, around the nares, coronary bands, and all four limbs. Various diagnostic tests were negative for swine vesicular disease virus, footand-mouth disease virus, vesicular exanthema of swine virus and vesicular stomatitis virus infection. However, vesicular scrapings and oral pharyngeal fluid were positive for the presence of Seneca Valley virus by RT-PCR.
\end{abstract}

Keywords: Picornavirus; RT-PCR; Seneca valley virus; Skin; Swine; Vesicles

Seneca Valley Virus (SVV) is a single-stranded RNA virus in the family Picornaviridae. It is closely related to the genus Cardiovirus, and has been recently proposed to be classified in the genus Senecavirus, along with other closely related porcine picornaviruses [1]. Seneca Valley virus is a newly discovered virus that was originally isolated as a contaminant in cell culture medium; its complete genome sequence and structure has been recently published $[1,2]$. Furthermore, SVV has been reported to be associated with cases of idiopathic vesicular disease in pigs originating from several different locations in Manitoba [3].

Several cases of non-debilitating erosions and vesicles on the snout, oral cavity, skin and coronary bands have been infrequently described in pigs over many years without an identifiable cause and thus, were grouped under Swine Idiopathic Vesicular Disease (SIVD) syndrome [4]. Outbreaks of SIVD are primarily observed between the spring and fall months [3]. SIVD grossly and histologically resembles vesicular foreign animal diseases, which are clinically and economically important. Cases of SIVD have been reported in New Zealand, Australia, Canada, Florida, Iowa and most recently Indiana [3,5-8]. In the most recent cases, vesicular foreign animal diseases were ruled out, and testing for other infectious diseases and microscopic evaluation of the lesions did not reveal a causative agent $[3,5]$. Similar vesicular lesions in pigs have been associated with the feeding of murine products in Australia and feeding of Sclerotinia sclarotiorum infected celery, parsnips and carrots from New Zealand $[7,8]$. Other potential causes for vesicular lesions in pigs include porcine parvovirus, porcine enterovirus group III, calicivirus (San Miguel sea lion virus), mycotoxins and contact dermatitis [9-13]. The purpose of this report is to provide more descriptive pathology obtained from an isolated and sporadic case of idiopathic vesicular disease in a pig. In this pig, SVV was identified from the vesicular lesions by using Reverse Transcription-Polymerase Chain Reaction (RT-PCR).

A 6-month-old intact male Chester White boar purchased at the Indiana State Fair was presented to the referring veterinarian in August, 2010 with a history of anorexia, lethargy and lameness. Intact and ruptured vesicles and erosions were observed in the oral cavity, around the nares and the coronary bands, and ulcers were observed on the fore limbs and hind limbs. Because of its clinical resemblance with the vesicular foreign animal diseases, diagnostic samples (serum, scrapings of vesicular lesions and oral pharyngeal fluid) were collected and analyzed at the Foreign Animal Disease Diagnostic Laboratory at Plum Island Animal Disease Center. Scrapings from vesicles and oral pharyngeal fluid were negative for Swine Vesicular Disease Virus (SVDV), Foot-And Mouth Disease Virus (FMDV), Vesicular Exanthema of Swine Virus (VESV) and Vesicular Stomatitis Virus (VSV) by real time RT-PCR. Serum from the pig also was tested for VESV by indirect fluorescent antibody (IFA), SVDV and VSV by antibody ELISA (ABELISA) and FMDV by AB-ELISA and Virus Infection Associated Antigen (VIAA) agar gel immunodiffusion. All of the samples tested were negative for these viruses. Virus isolation on the vesicular lesion scrapings and oral pharyngeal fluid was performed but failed to isolate any virus; however, these samples were positive for the presence of SVV by RT-PCR. Other pigs previously in contact with this animal did not show any clinical signs. Sera from five other contact pigs were tested for FMDV and SVDV as described above and were negative for evidence of these viruses.

Due to the progression of clinical signs, the boar was euthanized and presented for necropsy in September, 2010. Gross lesions included the formation of multifocal round, discrete $(0.5-4 \mathrm{~cm}$ in diameter) ulcerative and erosive lesions with overlying crusts on all four distal limbs. The lateral surfaces of the coronary bands of the lateral claws on both forelimbs had deep and chronic ulcers with crusting and sloughing of the hoof wall distal to these lesions (Figure 1). Within the oral cavity, there was a fluid-filled vesicle on the hard palate and multifocal chronic superficial and deep ulcers on the maxillary and mandibular buccal and gingival mucosa, and on the snout around the nares (Figure 2). Other

${ }^{* *}$ Corresponding author: Kuldeep Singh, Veterinary Diagnostic Laboratory, University of Illinois, Urbana-Champaign, IL 61802, USA, E-mail: ksingh08@illinois.edu

Received July 02, 2012; Accepted September 20, 2012; Published September 24, 2012

Citation: Singh K, Corner S, Clark SG, Scherba G, Fredrickson R (2012) Seneca Valley Virus and Vesicular Lesions in a Pig with Idiopathic Vesicular Disease. J Vet Sci Technol 3:123 doi:10.4172/2157-7579.1000123

Copyright: ( 2012 Singh K, et al. This is an open-access article distributed unde the terms of the Creative Commons Attribution License, which permits unrestricted use, distribution, and reproduction in any medium, provided the original author and source are credited. 


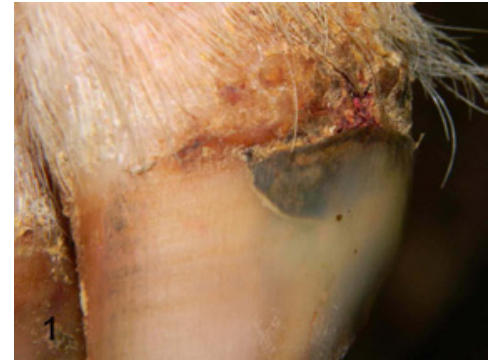

Figure 1: Hoof; boar. Interdigital region is ulcerated and thickened by hyperkeratosis, fibrosis, and crusting. The hoof wall distal to this lesion is sloughing.

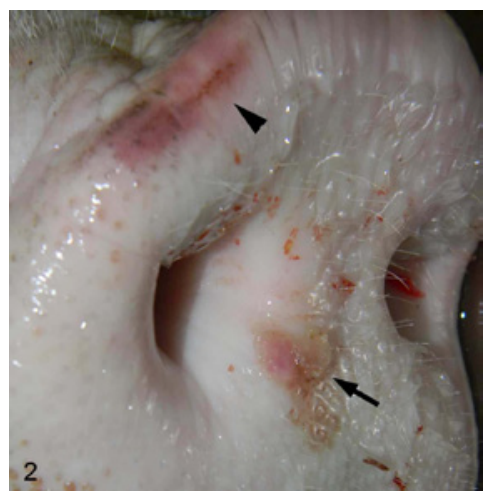

Figure 2: Snout; boar. A distinct ruptured vesicle (arrow) and intact vesicle (arrow head) are present.

gross lesions included serofibrinous peritonitis and pericarditis, locally extensive hemorrhagic jejunitis and a focal gastric ulcer.

Samples of small intestine were negative for Salmonella sp. by PCR. Aerobic and anaerobic bacterial culture of these samples did not yield any significant growth nor did aerobic bacterial culture of the spleen. Aerobic culture of an ulcerative lesion on the hind limb only produced moderate growth of Staphylococcus hyicus. Fluorescent antibody and virus isolation attempts for porcine parvovirus on the liver, kidney and spleen were negative. Other causes of vesicular disease also were ruledout using ultrastructural analysis, virus isolation, bacterial culture, and histopathology. Ultrastructural analysis (transmission and negativestaining) of the lesions for the presence of any virus particles, such as those for picornavirus, calicivirus, or enterovirus was also negative.

Microscopically, the epidermis surrounding the cutaneous lesions on the distal limbs exhibited both orthokeratotic and parakeratotic hyperkeratosis and epidermal hyperplasia. There also was regional ulceration and infiltration by numerous degenerate and intact neutrophils admixed with fibrin, edema, acute hemorrhages, and karyorrhectic nuclear debris (Figures 3 and 4). Occasionally, microcolonies of cocci bacteria were observed. Small numbers of neutrophils, lymphocytes and plasma cells extended into the perivascular regions of the dermis. In some regions, edema and early granulation tissue also expanded the dermis. Ulcerations with similar morphologic characteristics were present within the oral cavity and on the snout. Histopathology was not conducted on early vesicular lesions. It was assumed that the suppurative and ulcerative dermatitis described above represented areas where vesicles were reported antemortem, and were secondarily invaded by bacteria. Other microscopic findings included focal acute ulcerative gastritis, mild lymphoplasmacytic hepatitis as well as generalized and global membranoproliferative glomerulonephritis.

Ultrastructural analysis of the oral and skin lesions was performed using negative staining and transmission methods and both failed to demonstrate the presence of a virus.

This negative result could be due to the chronicity of the lesions. Moreover, an ultrastructure feature that helps in the identification of picornaviruses is their aggregation into lattices or crystallinearrays; if these viruses are individualized, they are very difficult to be identified [14]. Staphylococcus hyicus can cause exudative epidermitis in piglets; however, although it was cultured from the lesions, it was considered a secondary contaminant by virtue of its presence in the normal cutaneous flora. In addition, the signalment and clinical signs do not fit with the exudative epidermitis syndrome. We also observed membranoproliferative glomerulonephritis, which has not been previously reported in pigs suffering from SIVD. The causes of membranoproliferative glomerulonephritis are numerous but in general, it reflects chronic low-grade antigenemia, which could be due to a SVV infection or other antigens. It is possible that serofibrinous peritonitis and pericarditis and hemorrhagic jejunitis could be consequence of chronic renal failure. However, other lesions suggesting chronic renal failure were not observed.

To the best of our knowledge, this is the first case of SIVD with detailed description of lesions in which an etiologic association is made with the SVV. However, this virus has been previously isolated from the healthy pigs in several areas of the United States and it has not been reported to cause clinical disease in pigs or other mammals [1].Therefore, this association is purely speculative until further investigation is done and Koch's postulates have been fulfilled. Importantly, this is the second

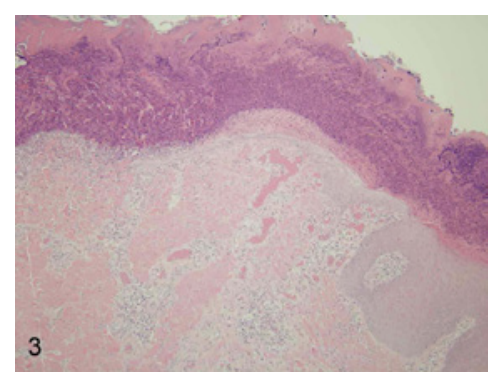

Figure 3: Haired skin; boar. The epidermis is regionally ulcerated and covered by a thick serocellular crust. The adjacent intact epidermis is markedly acanthotic. Hematoxylin and eosin (HE).

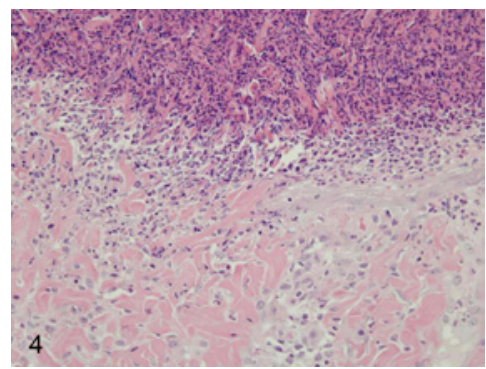

Figure 4: Haired skin; boar. The epidermis is ulcerated and covered by numerous degenerate and viable neutrophils admixed with small numbers of macrophages, karyorrhectic nuclear debris, and fibrin. The underlying dermis is infiltrated by small numbers of macrophages admixed with neutrophils. Hematoxylin and eosin (HE). 
Citation: Singh K, Corner S, Clark SG, Scherba G, Fredrickson R (2012) Seneca Valley Virus and Vesicular Lesions in a Pig with Idiopathic Vesicular Disease. J Vet Sci Technol 3:123 doi:10.4172/2157-7579.1000123

Page 3 of 3

report where SVV was identified in pigs with SIVD in which other etiologic agents were ruled-out, hence it is possible that SVV may be the causative agent of SIVD. Consequently, since SIVD is clinically and economically important due to its resemblance with vesicular foreign animal diseases, which are associated with significant morbidity and mortality in pigs, further investigation in to the possible association of SVV with this syndrome is warranted.

\section{Acknowledgements}

Authors wish to thank Dr. Fawzi Mohamed for molecular analysis of samples (Foreign Animal Disease Diagnostic Laboratory, Plum Island Animal Disease Center, Greenport, NY 11944, USA

\section{References}

1. Hales LM, Knowles NJ, Reddy PS, Xu L, Hay C, et al. (2008) Complete genome sequence analysis of Seneca Valley virus-001, a novel oncolytic picornavirus. J Gen Virol 89: 1265-1275.

2. Venkataraman S, Reddy SP, Loo J, Idamakanti N, Hallenback PL, et al. (2008) Structure of Seneca Valley Virus-001: An oncolytic picornavirus representing a new genus. Structure 16: 1555-1561.

3. Pasma T, Davidson S, Shaw SL (2008) Idiopathic vesicular disease in swine in Manitoba. Can Vet J 49: 84-85.

4. Cameron R (2006) Diseases of the Skin, Diseases of Swine. Blackwell Publ, Ames.
5. Amass SF, Schneider JL, Miller CA, Shawky SA, Stevenson GW, et al. (2004) Idiopathic vesicular disease in a swine herd in Indiana. J Swine Health Prod 12: $192-196$

6. Gibbs EPJ, Stoddard HL, Yedloutchnig RJ, House JA, Legge M (1983) A vesicular disease of pigs in Florida of unknown etiology. Florida Vet J 12: 25-27.

7. Montgomery JF, Oliver RE, Poole WS (1987) A vesiculo-bullous disease in pigs resembling foot and mouth disease I. Field cases. N Z Vet J 35: 21-26.

8. Munday BL, Ryan FB (1982) Vesicular lesions in swine - possible association with the feeding of murine products. Aust Vet J 59: 193

9. Harvey RB, Kubena LF, Corrier DE, Huff WE, Rottinghaus GE (1990) Cutaneous ulceration and necrosis in pigs fed aflatoxin- and T-2 toxin-contaminated diets. $J$ Vet Diagn Invest 2: 227-229.

10. Knowles NJ (1988) The association of group III porcine enteroviruses with epithelial tissue. Vet Rec 122: 441-442.

11. Kresse JI, Taylor WD, Stewart WW, Eernisee KA (1985) Parvovirus infection in pigs with necrotic and vesicle-like lesions. Vet Microbiol 10: 525-531.

12. Lager KM, Mengeling WL (1994) Porcine parvovirus associated with cutaneous lesions in piglets. J Vet Diagn Invest 6: 357-359.

13. Whitaker HK, Neu SM, Pace LW (1990) Parvovirus infection in pigs with exudative skin disease. J Vet Diagn Invest 2: 244-246.

14. Cheville N (1994) Ultrastructural pathology, an introduction to interpretation lowa State University Press 566-567. 